\title{
Mediator-Free SECM for Probing the Diffusion Layer pH with Functionalized Gold Ultramicroelectrodes
}

\author{
Mariana C. O. Monteiro, ${ }^{\dagger, \ddagger}$ Leon Jacobse, ${ }^{\ddagger} \S_{(0)}$ Thomas Touzalin, ${ }^{\dagger}$ and Marc T. M. Koper* ${ }^{\dagger}{ }^{\dagger}$ \\ ${ }^{\dagger}$ Leiden Institute of Chemistry, Leiden University, P.O. Box 9502, 2300 RA, Leiden, The Netherlands \\ ${ }^{\S}$ DESY NanoLab, Deutsches Elektronensynchrotron DESY, Notkestrasse 85, D-22607 Hamburg, Germany
}

Supporting Information

\begin{abstract}
Probing $\mathrm{pH}$ gradients during electrochemical reactions is important to better understand reaction mechanisms and to separate the influence of $\mathrm{pH}$ and $\mathrm{pH}$ gradients from intrinsic electrolyte effects. Here, we develop a $\mathrm{pH}$ sensor to measure $\mathrm{pH}$ changes in the diffusion layer during hydrogen evolution. The probe was synthesized by functionalizing a gold ultramicroelectrode with a self-assembled monolayer of 4nitrothiophenol (4-NTP) and further converting it to form a hydroxylaminothiophenol (4-HATP)/4-nitrosothiophenol (4NSTP) redox couple. The $\mathrm{pH}$ sensing is realized by recording the tip cyclic voltammetry and monitoring the Nernstian shift of the midpeak potential. We employ a capacitive approach technique in our home-built Scanning Electrochemical Microscope (SECM) setup in which an AC potential is applied to the sample and the capacitive current generated at the tip is recorded as a function of distance. This method allows for an approach of the tip to the electrode that is electrolyte-free and consequently also mediator-free. Hydrogen evolution on gold in a neutral electrolyte was studied as a model system. The $\mathrm{pH}$ was measured with the probe at a constant distance from the electrode (ca. $75 \mu \mathrm{m}$ ), while the electrode potential was varied in time. In the nonbuffered electrolyte used $\left(0.1 \mathrm{M} \mathrm{Li}_{2} \mathrm{SO}_{4}\right)$, even at relatively low current densities, a pH difference of three units is measured between the location of the probe and the bulk electrolyte. The time scale of the diffusion layer transient is captured, due to the high time resolution that can be achieved with this probe. The sensor has high sensitivity, measuring differences of more than $8 \mathrm{pH}$ units with a resolution better than $0.1 \mathrm{pH}$ unit.
\end{abstract}

$\mathrm{T}$ he $\mathrm{pH}$ affects chemical reactions in a wide variety of systems and $\mathrm{pH}$ effects have been studied in the fields of biology, ${ }^{1,2}$ medicine, ${ }^{3,4}$ corrosion, ${ }^{5,6}$ and electrocatalysis, ${ }^{7}$ among others. For example, during electrochemical reactions that consume or produce either protons or hydroxyl ions, a $\mathrm{pH}$ gradient is built up in the diffusion layer. The proton concentration at the electrode-electrolyte interface is known to influence the kinetics and selectivity of various electrochemical reactions such as hydrogen evolution, ${ }^{8} \mathrm{CO}_{2}$ reduction, ${ }^{9,10}$ nitrate reduction, ${ }^{11}$ and oxygen evolution. ${ }^{12}$ Measuring the $\mathrm{pH}$ near the surface allows to better model these electrocatalytic processes and to understand their mechanism under different reaction conditions and in different electrolytes. In order to probe the diffusion layer, the spatial resolution of the conventional $\mathrm{pH}$ glass electrode and other bulk techniques using optical ${ }^{13}$ or colorimetric ${ }^{14}$ sensors is not high enough. Instead, local measurements of $\mathrm{pH}$ at the microand nanoscale can be achieved with Scanning Electrochemical Microscopy (SECM) where miniaturized electrodes are used to probe the local properties of an interface. ${ }^{15}$ High spatial and temporal resolution of these measurements can be achieved, which mainly depend on the kind of probe used and the electrochemical signal monitored. Spectroscopic $\mathrm{pH}$ measurements at the microscale have also been reported. ${ }^{16-18}$
However, such measurements do not probe the local proton concentration directly, can only be used for specific electrodes and electrocatalytic reactions, and do not provide spatial resolution. Fluorescence microscopy ${ }^{19-21}$ has also been used to map interfacial $\mathrm{pH}$. Although $\mathrm{pH}$ maps can be obtained relatively quickly, the need of adding a fluorophore to the electrolyte is a drawback as it may affect the electrochemical process being studied. Based on the discussion presented here, SECM should be a more suitable technique to measure the interfacial $\mathrm{pH}$ during electrocatalytic reactions.

Different probes have been proposed for conducting local $\mathrm{pH}$ measurements with SECM. Various transition metal oxides show a super Nernstian open circuit potential (OCP) shift with $\mathrm{pH}$ and have been employed as potentiometric $\mathrm{pH}$ sensors. Iridium oxide $\left(\mathrm{IrO}_{x}\right)$ is the most commonly used ${ }^{22}$ and several synthesis methods have been reported such as nanoparticles electrodeposition, ${ }^{23}$ anodic growth, ${ }^{24}$ and solgel synthesis. ${ }^{25}$ The sensing response relies on the porosity of the oxide layer; dense oxide films have a slow response to $\mathrm{pH}$ changes, while porous layers show a fast response, but with a

Received: October 30, 2019

Accepted: December 25, 2019

Published: December 25, 2019 
significant OCP drift. $^{26}$ Besides drift, another drawback of these probes comes from the adsorption of species on the sensor surface (contaminants, ions, reaction products) that can lead to a convoluted OCP response. ${ }^{27}$ These limitations can strongly influence how precisely these $\mathrm{IrO}_{x} \mathrm{pH}$ sensors capture the local $\mathrm{pH}$ gradient during electrochemical reactions. In addition, oxide dissolution can compromise the use of these probes in highly acidic or alkaline media. ${ }^{28}$ To overcome these limitations, polymer-based potentiometric sensors ${ }^{29}$ have been proposed, such as polyaniline-coated $\mathrm{Au}$ electrodes, ${ }^{30}$ and carbon electrodes modified with poly(1-naphthylamine $)^{31}$ or polydopamine. $^{32}$ However, many of these polymer films strongly interact with alkali metal cations which may lead to a shift in the OCP. ${ }^{33}$ In addition, the time response is reported to strongly depend on the quality of the electropolymerization and film thickness.

Other techniques have also been used to probe the $\mathrm{pH}$ near the surface. Ryu et al. used the $\mathrm{pH}$-sensitive reaction of $\mathrm{H}_{2}$ with cis-2-butene-1,4-diol to probe the interfacial $\mathrm{pH}$ during concurrent hydrogen oxidation. ${ }^{34}$ Even though significant effects were observed as a function of buffer capacity and current density, the impact of the addition of cis-2-butene-1,4diol to the electrolyte on the electrocatalysis cannot be determined and might limit the use of this technique to probe other reactions. Measurements of local $\mathrm{pH}$ have also been performed using a Rotating Ring-Disk Electrode (RRDE). ${ }^{35,36}$ However, this method is limited in terms of the electrode materials, reactions to be analyzed, and lack spatial resolution. Voltammetric $\mathrm{pH}$ sensors have also been proposed and are interesting due to their fast response and operation in large $\mathrm{pH}$ ranges. ${ }^{37-40}$ Boltz and co-workers, for instance, used the voltammetry of platinum nanoelectrodes to monitor the $\mathrm{pH}$ above a gas diffusion electrode during oxygen reduction. ${ }^{41}$ However, platinum can only be used to probe reactions that do not generate species that strongly interact with the surface, affecting the voltammetry. Michalak et al. developed nano $\mathrm{pH}$ sensors based on the cyclic voltammetry of syringaldazine polymer films attached to carbon substrates. ${ }^{42}$ Even though the sensor works in a large $\mathrm{pH}$ range, the stability of polymer films, in general, is still concerning, as film detachment can hinder the $\mathrm{pH}$ response.

In this work, we present a $\mathrm{pH}$ sensor based on the irreversible self-assembly of 4-nitrothiophenol on a gold ultramicroelectrode (Au-UME). After conversion, the hydroxylaminothiophenol/4-nitrosothiophenol redox couple is formed and its midpeak potential shows a Nernstian shift of $57 \mathrm{mV} / \mathrm{pH}$. Using hydrogen evolution as a model system, we can perform $\mathrm{pH}$ measurements in the diffusion layer with high reproducibility. Because of the sensitivity of the functionalized tip and to avoid possible side effects from redox-active mediators, we also introduce an ex situ capacitive approach method to control the absolute tip-to-sample distance. ${ }^{43}$ In contrast to potentiometric $\mathrm{pH}$ sensors, our probe provides high time resolution and stable response. In addition, the $\mathrm{pH}$ sensitivity is not affected by electrolyte species or reaction products, which allows for application in a wide variety of systems (electrocatalytic or not).

\section{EXPERIMENTAL SECTION}

pH Sensor Fabrication and Characterization. Gold ultramicroelectrodes (Au-UMEs) were fabricated by sealing a gold wire $(50 \mu \mathrm{m}$ diameter, $\mathrm{H}$. Drijfhout en Zoon's Edelmetaalbedrijven B.V.) in a glass capillary $(0.4 \mathrm{~mm}$ i.d.,
Drummond Scientific Co.) and exposing a cross section by grinding the electrode with a silicon carbide paper (grit size 600, MaTeck). The surface was prepared by polishing with a 1 , 0.25 , and $0.05 \mu \mathrm{m}$ diamond suspension (MetaDi, Buehler) for $2 \mathrm{~min}$. In between each polishing step the electrode was sonicated (Bandelin Sonorex RK 52H) in ultrapure water (>18.2 $\mathrm{M} \Omega \mathrm{cm}$, Millipore Milli-Q) for $5 \mathrm{~min}$ and, after the last step, $5 \mathrm{~min}$ in ethanol followed by $15 \mathrm{~min}$ in water. After surface preparation, the electrode was characterized by cyclic voltammetry in $0.1 \mathrm{M} \mathrm{H}_{2} \mathrm{SO}_{4}$, recorded in a one compartment cell $(20 \mathrm{~mL})$ using a gold wire $(0.5 \mathrm{~mm}$ diameter, MaTeck, 99.9\%) as counter electrode and $\mathrm{Ag} / \mathrm{AgCl}$ (LowProfile, Pine Research Instrumentation) reference electrode. The electrochemical measurements reported in this work were performed using a Bio-Logic 2-channel potentiostat/galvanostat/EIS (SP300). The Au-UMEs were modified with 4-nitrothiophenol (4NTP, Merck, $80 \%$ ) by immersion in a $1 \mathrm{mM} 4-\mathrm{NTP} /$ ethanol solution. After $20 \mathrm{~min}$, the electrode was thoroughly rinsed with ethanol and ultrapure water in order to remove weakly adsorbed species. The functionalized electrode was transferred back to a $0.1 \mathrm{M} \mathrm{H}_{2} \mathrm{SO}_{4}$ solution in order to convert the organic molecule by polarization from 0.1 to $-0.25 \mathrm{~V}$ versus $\mathrm{Ag} / \mathrm{AgCl}$ $\left(100 \mathrm{mV} \mathrm{s}^{-1}\right)$. Calibration of the $\mathrm{pH}$ sensor was performed by cyclic voltammetry in $0.1 \mathrm{M} \mathrm{Li}_{2} \mathrm{SO}_{4}$ (Alfa Aesar, anhydrous, 99.99\% metal basis) solutions saturated with argon or hydrogen at various $\mathrm{pH}$. The $\mathrm{pH}$ was adjusted by the addition of appropriate amounts of $1 \mathrm{M} \mathrm{H}_{2} \mathrm{SO}_{4}$ (Merck, Suprapur, 96\%) or $1 \mathrm{M} \mathrm{LiOH}$ (Merck, monohydrate, $99.995 \%$ trace metals basis). The $\mathrm{pH}$ of the calibration solutions was determined with a glass-electrode $\mathrm{pH}$ meter (Lab 855, SI Analytics) calibrated with standard buffer solutions (Radiometer Analytical).

SECM Measurements. SECM experiments were performed in a home-built system equipped with $x-y-z$ stepper motors (C-863 Mercury, PI) and piezo positioners (E-665, PI). The sample was a gold disc $(0.5 \mathrm{~mm}$ thick, MaTeck, 99.995\%) cleaned and polished with diamond suspension using the protocol described elsewhere. ${ }^{44}$ A copper plate $(0.5$ $\mathrm{mm}$ thick, MaTeck) is used to make the electrical contact to the sample. A schematic representation of the SECM setup and a more detailed description can be found in Figure S1 in the Supporting Information.

The glass SECM cell and gas bubblers were cleaned by immersion in potassium permanganate solution for $24 \mathrm{~h}$ $\left(1 \mathrm{~g} \mathrm{~L}^{-1} \mathrm{KMnO}_{4}\right.$ dissolved in $\left.0.5 \mathrm{M} \mathrm{H}_{2} \mathrm{SO}_{4}\right)$, followed by immersion in dilute piranha solution in order to remove residues of manganese oxide and permanganate anions. The glassware was further cleaned by boiling at least five times in ultrapure water.

The mediator-free approach of the modified $\mathrm{Au}$-UME to the gold working electrode was performed in air by applying a 10 $\mathrm{kHz}$ AC voltage with an amplitude of $4 V_{\mathrm{pp}}\left(1.41 V_{\mathrm{RMS}}\right)$ to the sample using a function generator (33210A, Keysight). The gold ultramicroelectrode was connected to a low noise current preamplifier (SR570, Stanford Research) operated at highbandwidth with a gain of $2 \times 10^{8} \mathrm{~V} \mathrm{~A}^{-1}$. The capacitive tip current was obtained using a virtual lock-in amplifier (LabView).

To measure the $\mathrm{pH}$ during hydrogen evolution, the SECM electrochemical cell was filled with $5 \mathrm{~mL}$ of $0.1 \mathrm{M} \mathrm{Li}_{2} \mathrm{SO}_{4}$ brought to $\mathrm{pH} 3.2$ by the addition of an adequate amount of 1 $\mathrm{M} \mathrm{H}_{2} \mathrm{SO}_{4}$. The experiment was performed in a six-electrode configuration, where the tip and the sample were controlled by 
two distinct potentiostat channels. Two gold wires and two $\mathrm{Ag} / \mathrm{AgCl}$ electrodes were used as counter and reference electrodes, respectively. Argon was purged through and above the solution throughout the whole experiment in order to avoid oxygen diffusion into the electrolyte. Measurements were performed with the $\mathrm{pH}$ sensor at a constant distance from the surface and the tip voltammetry was constantly recorded at a scan rate of $200 \mathrm{mV} \mathrm{s}^{-1}$ (5 s per cycle) while the sample potential was varied. The midpeak potential for each cycle was obtained by fitting the tip voltammetry (see SI) and converted to $\mathrm{pH}$ using the calibration curve.

\section{RESULTS AND DISCUSSION}

Functionalized Gold pH Sensor. It has been previously shown how important the surface preparation and cleanliness of UMEs is for their use in electrocatalysis. ${ }^{45}$ Au-UMEs were characterized in $0.1 \mathrm{M} \mathrm{H}_{2} \mathrm{SO}_{4}$ before functionalization (see Figure S2 in SI) in order to ensure the glass is efficiently sealing the gold wire and that the surface is clean. Functionalization was performed by immersing the probe in a solution containing 4-nitrothiophenol (4-NTP). The molecules form a self-assembled monolayer at the gold surface, binding through the thiol anchor group. The free nitro group is then partially reduced electrochemically into a hydroxyl amino group by cycling the tip from 0.1 to $-0.25 \mathrm{~V}$ versus $\mathrm{Ag} / \mathrm{AgCl}$ in $0.1 \mathrm{M} \mathrm{H}_{2} \mathrm{SO}_{4}$. The voltammogram $(\mathrm{CV})$ of the conversion and a schematic representation of the species formed are shown in Figure 1a and b, respectively. Hydroxylaminothio-

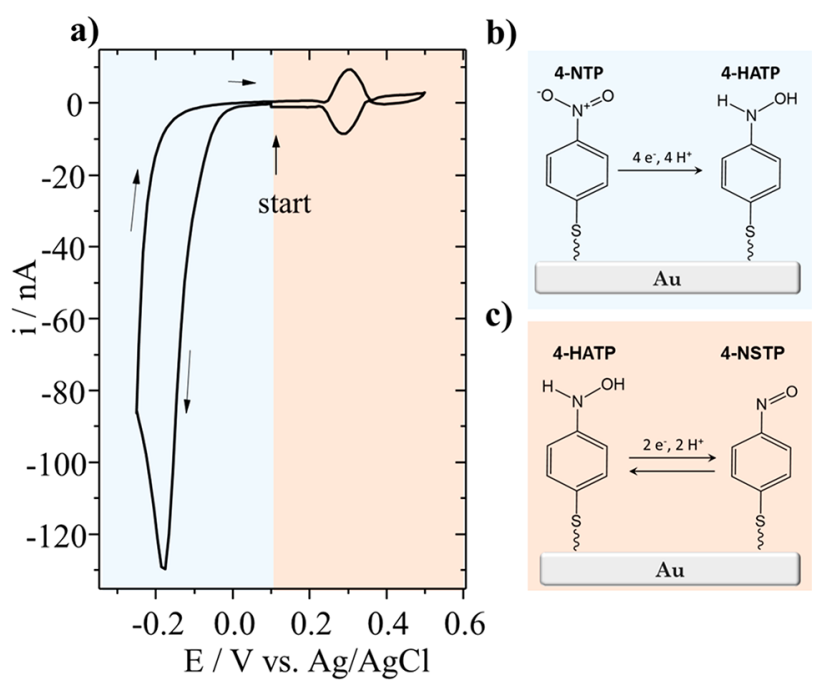

Figure 1. (a) Voltammetry $\left(0.1 \mathrm{M} \mathrm{H}_{2} \mathrm{SO}_{4}, 100 \mathrm{mV} \mathrm{s}^{-1}\right)$ and schematic representation of the conversion of (b) 4-nitrothiophenol (4-NTP) to 4-hydroxiaminothiophenol (4-HATP), and (c) the two proton-two electron transfer reaction of the redox couple 4-HATP/ 4-NSTP.

phenol (4-HATP) is formed through the transfer of four protons and four electrons and at positive potentials 4-HATP is reversibly oxidized to 4-nitrosothiophenol (4-NSTP) through the transfer of two protons and two electrons (see Figure 1c). Thus, the midpeak potential of the 4-HATP/4NSTP redox couple is expected to show a Nernstian shift with $\mathrm{pH}^{46}$

The electrochemical characterization of the reversible redox couple 4-HATP/4-NSTP in Figure 2a shows that the tip voltammetry is very stable over the 30 cycles performed. It is a)

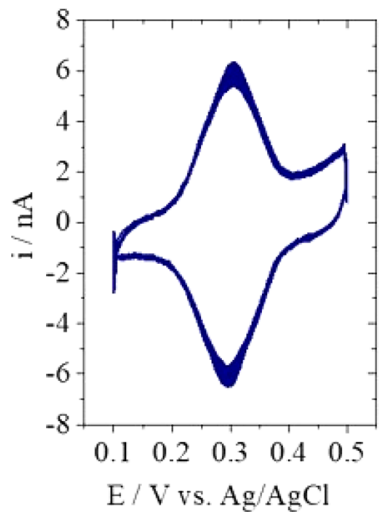

b)

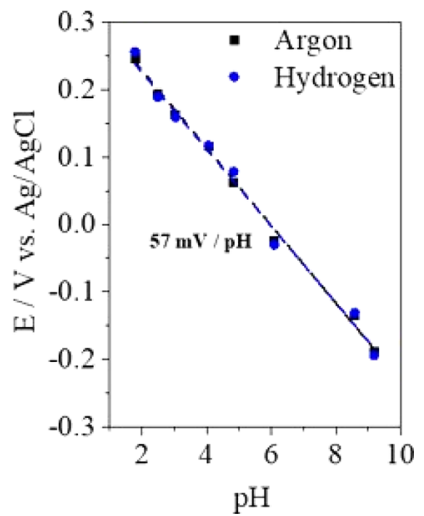

Figure 2. (a) Characterization of the electroactive redox couple 4HATP/4-NATP in $0.1 \mathrm{M} \mathrm{H}_{2} \mathrm{SO}_{4}$ at $200 \mathrm{mV} \mathrm{s}^{-1}$, and (b) calibration of the functionalized $\mathrm{Au}-\mathrm{UME}$ in $0.1 \mathrm{M} \mathrm{Li}_{2} \mathrm{SO}_{4}$ solutions adjusted to different $\mathrm{pH}$ and saturated with argon or hydrogen.

important to point out that for successful functionalization of the Au-UME the potential of the tip must be carefully controlled. It has been previously shown by Touzalin et al. that at potentials lower than $-0.25 \mathrm{~V}$ vs $\mathrm{Ag} / \mathrm{AgCl}(\mathrm{pH}=1) 4-\mathrm{NTP}$ and 4-HATP are fully irreversibly reduced to 4-aminothiophenol (4-ATP). ${ }^{47}$ At potentials higher than $0.6 \mathrm{~V}$ vs $\mathrm{Ag} / \mathrm{AgCl}$ the monolayer is destabilized leading to a decrease in the 4-HATP/4-NSTP signal intensity (although the exact mechanism that leads to destabilization is not yet clear).

In order to calibrate the $\mathrm{pH}$ sensor, the tip voltammetry was recorded in argon saturated solutions of various $\mathrm{pH}$ values (see Figure S3 in the SI). The potential of the anodic peak as a function of $\mathrm{pH}$ was used to construct the calibration curves depicted in Figure $2 \mathrm{~b}$. A linear fit of the data provides the following relationship: $\mathrm{pH}=\left(0.341-E_{\text {peak }}\right) / 0.057$, with an $R^{2}$ value of 0.99 . The midpeak potential shows a Nernstian behavior with a shift of $57 \mathrm{mV}$ per $\mathrm{pH}$ unit. As the tip will be used to probe $\mathrm{pH}$ changes during hydrogen evolution, it was also calibrated in hydrogen atmosphere. As can be seen in Figure $2 b$, the presence of hydrogen does not affect the $\mathrm{pH}$ response. Even though the calibration curve shown in Figure $2 \mathrm{~b}$ does not include $\mathrm{pH} 7$, other calibration curves were made where $\mathrm{pH} 7$ was included and different from the work of Cobb et al. $^{48}$ on quinone-based $\mathrm{pH}$ electrodes, no significant deviation of the Nernstian response was found. The latter is probably related to the different interaction the quinone has with the substrate in comparison to the 4-nitrothiophenol selfassembled monolayer. In addition, 4-nitrothiophenol is only partially converted to 4-hydroxiaminothiophenol, and according to Cobb's work, the lower the coverage of the surface, the lower the deviations.

Mediator-Free Approach. Commonly used SECM approach techniques need a mediator or a diffusion limited reaction taking place at the tip in order to determine the tip-tosample distance. ${ }^{49}$ However, these methods are not ideal, because they can contaminate the electrocatalytic system and destabilize the self-assembled monolayer. Furthermore, it has been shown that commonly made assumptions about the exact tip geometry lead to significant errors in the calculated tip-tosample distance. ${ }^{50}$ In principle, AC-SECM ${ }^{51,52}$ could be employed, however, it is not known how stable the selfassembled monolayer is at high frequencies. Therefore, we have applied an electrolyte-free approach method that allows 
determining the absolute tip-to-surface distance without destabilizing the 4-NTP/4-HATP/4-NSTP monolayer. This ex situ method employs the capacitance between tip and sample and was recently introduced by De Voogd et al. as a preapproach for STM setups. ${ }^{43}$

To enable the determination of the tip-sample capacitance in air, an $\mathrm{AC}$ potential $\left(10 \mathrm{kHz}, 1.41 \mathrm{~V}_{\mathrm{RMS}}\right)$ is applied to the sample and the resulting tip current is followed with a preamplifier. The out-of-phase $(Y)$ component of the tip current is determined using a lock-in amplifier. Figure 3a
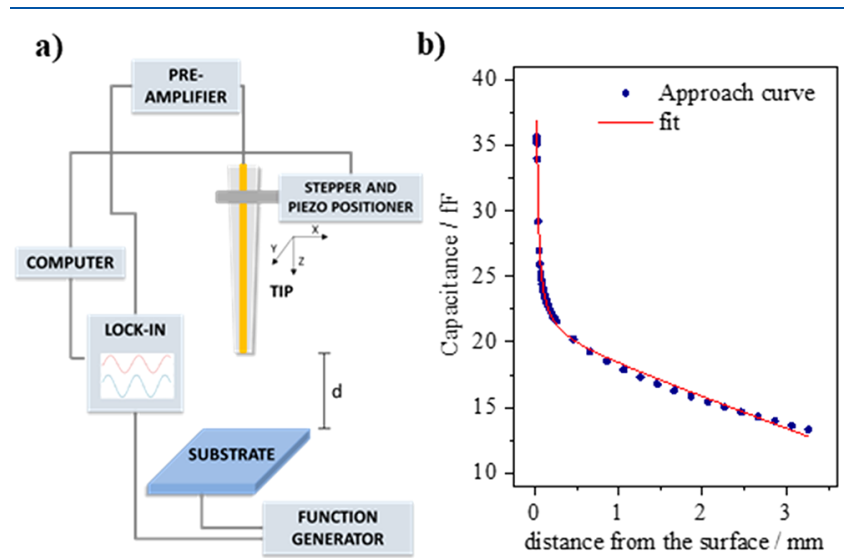

Figure 3. (a) Capacitive approach configuration and (b) approach curve obtained (blue circles) with its fit to eq 3 (red line).

shows a schematic representation of the approach configuration. The capacitance can be calculated via

$$
C_{\text {tot }}=\frac{Y}{2 \pi f G V}
$$

where $G$ is the preamplifier gain and $f$ and $V$ are the frequency and amplitude of the reference (sample) signal, respectively. The tip and sample can be described as a parallel plate capacitor, of which the capacitance is

$$
C_{\mathrm{par}}=\frac{\varepsilon_{0} A}{d}
$$

where $\varepsilon_{0}$ is the permittivity of air, $A$ is the area (of the tip), and $d$ is the tip-to-sample distance. The total measured capacitance also contains contributions that are inherent to the setup, for example, due to the tip connection far away from the sample and the connections used. ${ }^{43}$ These contributions can be well approximated with a linear function of distance $d$. $C_{\text {tot }}$ can thus be fitted with the following equation:

$$
C_{\text {tot }}(Z)=\left(\frac{\varepsilon \mathrm{A}}{d_{0}-Z}\right)+b^{*} Z+c
$$

where $Z$ is the position of the stepper motor varied during the approach, $d_{0}$ is the absolute surface position, and $b$ and $c$ are scaling parameters for the additional contributions. Figure $3 \mathrm{~b}$ shows a measured approach curve together with its fit, demonstrating clearly that the measured capacitance at short distances is dominated by $C_{\text {par }}$. This enables us to approach the surface to a distance well below the tip diameter (here, 10-30 $\mu \mathrm{m}$ with a $50 \mu \mathrm{m}$ diameter tip) in a safe and reproducible way. The fitting parameter $d_{0}$ allows to obtain the absolute tip-tosurface distance. It is important to point out that the shape of the approach curve is not affected by the probe RG (radius of the insulating layer divided by the radius of the active layer), which means that it can be employed in any SECM setup. It should be noted that, due to humidity, the measured permittivity $(\varepsilon)$ differs from the permittivity of dry air $\left(\varepsilon_{0}\right)$. In a Kelvin probe approach, this is known to significantly change the approach curve. ${ }^{53}$ However, as seen from eq 3 , it is clear that for the capacitive approach only the absolute capacitance changes as a function of $\varepsilon$, while the shape of the approach curve remains the same. Finally, we have successfully tested this approach technique with electrodes of different geometries and dimensions. With the appropriate electronics, the capacitive approach can also be used for significantly smaller tips than presented here. However, one should realize that, as the shape of the approach curve does not depend on the tip diameter, without detailed tip characterization the accuracy of this method is in the range of $3-5 \mu \mathrm{m}$.

pH Measurements. The functionalized gold $\mathrm{pH}$ sensor was used to study hydrogen evolution (HER) on gold (0.1 M $\mathrm{Li}_{2} \mathrm{SO}_{4}, \mathrm{pH}=3.2$ ) as a model system. Before the $\mathrm{pH}$ measurements were performed, the CV of HER was recorded at the gold substrate, which is shown in Figure 4. The cathodic

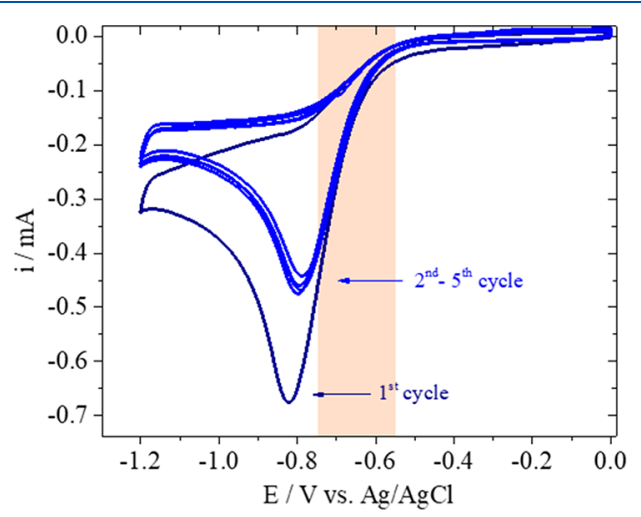

Figure 4. Cyclic voltammogram of hydrogen evolution taking place at the gold sample in $0.1 \mathrm{M} \mathrm{Li}_{2} \mathrm{SO}_{4}(\mathrm{pH}=3.2)$ recorded at $100 \mathrm{mV} \mathrm{s}^{-1}$.

current observed is due to the reduction of protons $\left(2 \mathrm{H}^{+}+2 \mathrm{e}^{-}\right.$ $\left.\rightarrow \mathrm{H}_{2}\right)$. The reaction rate is initially governed by kinetics and below $-0.8 \mathrm{~V}$ versus $\mathrm{Ag} / \mathrm{AgCl}$, the reaction becomes diffusion limited. As protons are consumed at the interface and the diffusion layer thickness increases, a $\mathrm{pH}$ gradient is built up. This can be observed in the CV by the decrease of the cathodic current from the first to the subsequent cycles due to proton depletion. However, quantification of the local $\mathrm{pH}$ is not possible based on the $\mathrm{CV}$ alone. At potentials more negative than $-1.2 \mathrm{~V}$ versus $\mathrm{Ag} / \mathrm{AgCl}$ and bulk $\mathrm{pH}$, mainly the reduction of water would take place $\left(2 \mathrm{H}_{2} \mathrm{O}+2 \mathrm{e}^{-} \rightarrow \mathrm{H}_{2}+\right.$ $2 \mathrm{OH}^{-}$). The SECM pH measurements were performed in the potential range highlighted in the $\mathrm{CV}$, in which only proton reduction is taking place.

SECM $\mathrm{pH}$ measurements were carried out with the functionalized Au-UME placed at fixed distance, $75 \pm 2 \mu \mathrm{m}$ from the surface. Hydrogen evolution was turned "on" and "off" at the gold sample while the tip voltammetry was recorded at a scan rate of $200 \mathrm{mV} \mathrm{s}^{-1}$. An example of the shift observed in the tip voltammetry can be found in Figure S4 in the SI. The tip CVs were fitted and the potential of the anodic peak determined as a function of time (see Figure S5). The calibration curve shown in Figure 2 was used to convert the tip peak potentials to $\mathrm{pH}$. Details on the data fitting can be found 
in the Supporting Information. Results depicted in Figure 5 show the $\mathrm{pH}$ changes taking place when HER is turned "on" a)

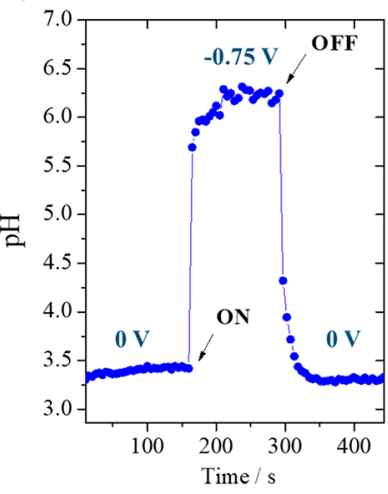

b)

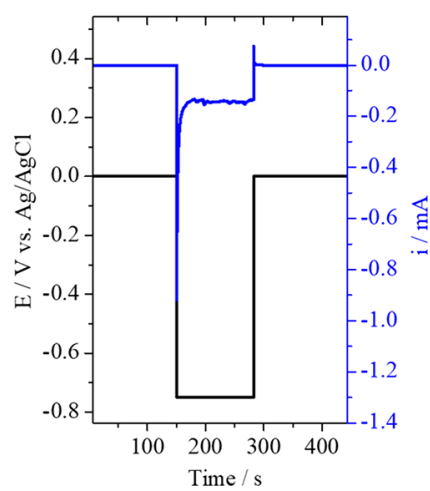

Figure 5. (a) $\mathrm{pH}$ measurement during hydrogen evolution in $0.1 \mathrm{M}$ $\mathrm{Li}_{2} \mathrm{SO}_{4}(\mathrm{pH}=3.2)$ with the sample at $-0.75 \mathrm{~V}$ vs $\mathrm{Ag} / \mathrm{AgCl}$; (b) chronoamperometry recorded at the sample.

and "off" at the sample at $-0.75 \mathrm{~V}$ versus $\mathrm{Ag} / \mathrm{AgCl}$. Each data point corresponds to the midpeak potential extracted from each $\mathrm{Au}-\mathrm{UME} \mathrm{CV}$. At $-0.75 \mathrm{~V}$ versus $\mathrm{Ag} / \mathrm{AgCl}$, protons are being consumed at the gold working electrode and it can be seen that the $\mathrm{pH}$ has an initial fast increase of more than two units and takes $50 \mathrm{~s}$ to reach a stable value. By observing the sample chronoamperometry curve (Figure $5 \mathrm{~b}$ ), it can be seen that this is also the time needed for the current to reach diffusion limitation due to an initially fast increase in local $\mathrm{pH}$ and diffusion layer thickness. At $-0.75 \mathrm{~V}$, the maximum $\mathrm{pH}$ value of 6.3 was reached. This strong $\mathrm{pH}$ increase can be explained by the fact that the electrolyte is not buffered. After $150 \mathrm{~s}, \mathrm{HER}$ is turned "off” and the near-surface $\mathrm{pH}$ returns to the bulk $\mathrm{pH}$ value. Similar measurements were previously performed with an $\mathrm{IrO}_{x}$ sensor. ${ }^{54}$ Comparing our results with the data presented in Figure 8 of ref 54, it can be seen that our probe captures the time scale of the $\mathrm{pH}$ changes during HER more precisely, allowing for a larger number of data points to be obtained in time, only dependent on the scan rate at which the tip voltammetry is recorded. In addition, our $\mathrm{pH}$ sensor is more stable and the response does not drift in time, which is a common drawback of potentiometric sensors such as $\mathrm{IrO}_{x}$.

Measurements were also performed at less negative sample potentials that, due to the slower consumption of protons, should lead to lower $\mathrm{pH}$ values than obtained at $-0.75 \mathrm{~V}$ versus $\mathrm{Ag} / \mathrm{AgCl}$. As depicted in Figure 6 when $-0.65 \mathrm{~V}$ versus $\mathrm{Ag} / \mathrm{AgCl}$ is applied to the sample, the $\mathrm{pH}$ reaches 4.75 , and when HER is carried out at $-0.55 \mathrm{~V}$ versus $\mathrm{Ag} / \mathrm{AgCl}$, only a small increase of less than one $\mathrm{pH}$ unit is observed. The corresponding sample chronoamperometry can be seen in Figure S6 in the SI. In order to ensure reproducibility of the $\mathrm{pH}$ response, a second measurement was performed applying the same negative potentials (black curve in Figure 6). It can be seen that the same $\mathrm{pH}$ values were reached for the same potentials. This also shows how thermal drift does not compromise the measurements.

Another set of HER experiments was performed where the sample potential was changed in smaller steps, to demonstrate the sensitivity of the $\mathrm{pH}$ probe. The results can be seen in Figure 7, where the sample potential was varied from -0.6 to $-0.9 \mathrm{~V}$ vs $\mathrm{Ag} / \mathrm{AgCl}$ in steps of $50 \mathrm{mV}$. The electrolyte bulk $\mathrm{pH}$ was 3 and a gradual increase in $\mathrm{pH}$ can be observed as a

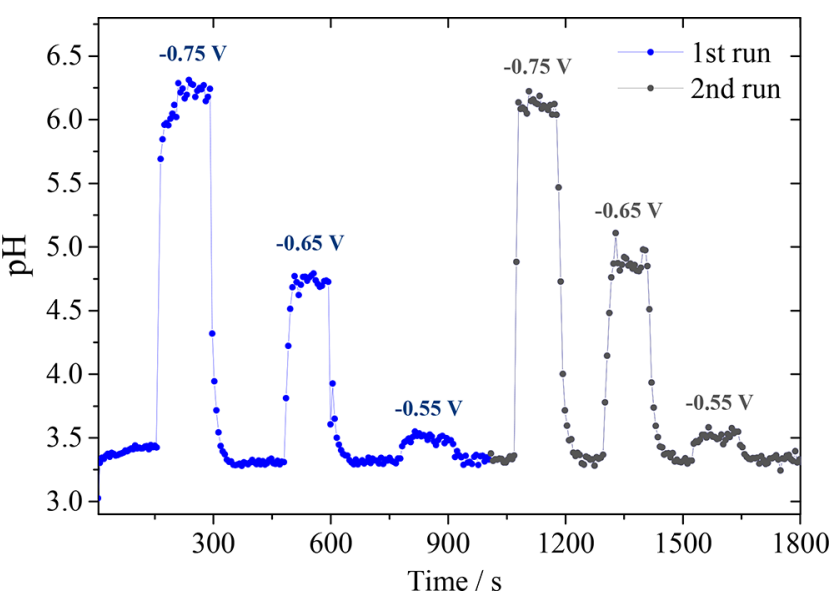

Figure 6. $\mathrm{pH}$ measurements in the diffusion layer during hydrogen evolution in $0.1 \mathrm{M} \mathrm{Li}_{2} \mathrm{SO}_{4}(\mathrm{pH}=3.2)$ at different sample potentials. The measurement was performed in duplicate.

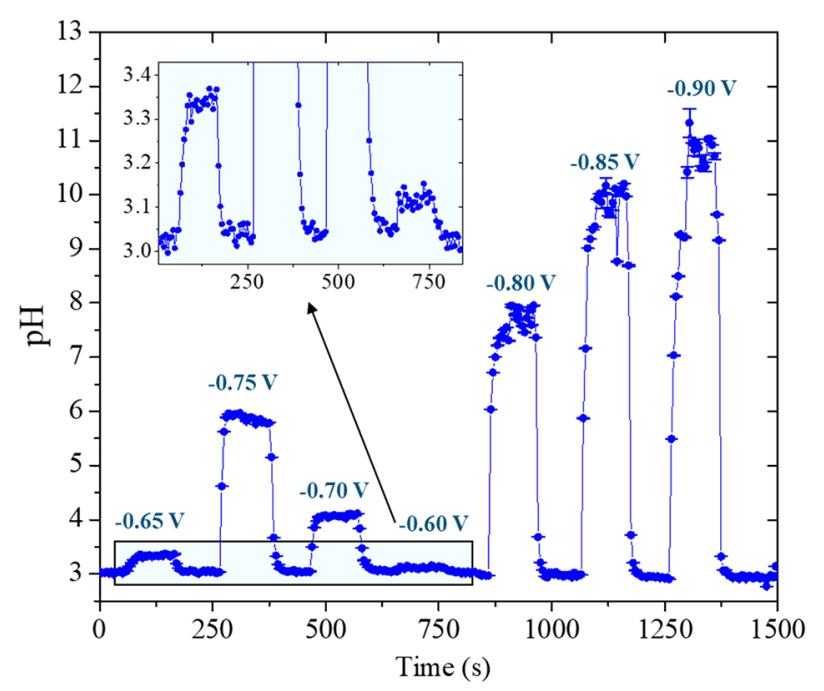

Figure 7. $\mathrm{pH}$ measurements in the diffusion layer during hydrogen evolution in $0.1 \mathrm{M} \mathrm{Li}_{2} \mathrm{SO}_{4}(\mathrm{pH}=3)$ performed in a wider potential range. The inset shows the small $\mathrm{pH}$ differences recorded when the sample potential was -0.65 and $-0.60 \mathrm{~V}$ vs $\mathrm{Ag} / \mathrm{AgCl}$.

function of sample potential, irrespective of the fact that the potentials are applied in a random order. The sample chronoamperometry recorded during the experiment can be found in Figure S7 in the SI. The inset in Figure 7 shows the remarkable sensitivity of our $\mathrm{pH}$ probe, as differences of 0.1 and $0.35 \mathrm{pH}$ units were recorded when the sample potential was -0.6 and $-0.65 \mathrm{~V}$ versus $\mathrm{Ag} / \mathrm{AgCl}$, respectively. In addition, measurements at more negative sample potentials show the large $\mathrm{pH}$ range at which the probe can be employed. Note that the absolute $\mathrm{pH}$ values cannot directly be compared between this measurement and the one shown in Figure 6 as different spots of the polycrystalline gold sample have distinct reactivities toward HER and the starting bulk $\mathrm{pH}$ is not the same.

It is important to point out that during the measurements, the potential window of the tip voltammetry must be adjusted due to the $\mathrm{pH}$ changes happening locally. Not only the 4HATP/4-NSTP midpeak potential shifts with $\mathrm{pH}$ but also the potential at which the unwanted tip reactions take place, that is, 4-ATP formation and destabilization of the self-assembled 
monolayer. Therefore, the 4-HATP/4-NSTP peak intensity would decrease drastically if the potential limits are not adjusted accordingly. In addition, the time resolution of the measurement can be adjusted according to the time scale of the reaction being studied (test CVs were recorded until up to $600 \mathrm{mV} \mathrm{s}^{-1}$ and the tip voltammetry was still stable).

\section{CONCLUSIONS}

In this work, we have successfully developed a $\mathrm{pH}$ sensor based on the self-assembly of 4-nitrothiphenol on gold ultramicroelectrodes. The probe voltammetry shows a Nernstian behavior with $57 \mathrm{mV} / \mathrm{pH}$ shift, which is not affected by the electrolyte composition. To ensure cleanliness and avoid destabilization of the probe, we employ a mediator- and electrolyte-free capacitive approach in order to determine the absolute tip-to-sample distance. We have measured the $\mathrm{pH}$ during hydrogen evolution with the tip placed at a constant distance, $75 \mu \mathrm{m}$ from the surface. Results show that our $\mathrm{pH}$ probe provides superior time resolution compared to previously reported potentiometric $\mathrm{IrO}_{x} \mathrm{pH}$ sensors, allowing to capture the dynamics of proton diffusion during hydrogen evolution. A gold UME of $50 \mu \mathrm{m}$ diameter was used in this work, but the functionalization with 4-NTP can also be carried out using smaller gold UMEs for further spatially resolved measurements. This would also allow for measurements with the probe positioned closer to the surface. Summarizing, we presented a highly sensitive and selective miniature $\mathrm{pH}$ probe that can be applied to a wide variety of systems, changing for example the gas atmosphere, electrolyte composition, and substrate. This work provides the means for more precise determination of the spatially resolved diffusion layer $\mathrm{pH}$ under different reactions. Consequently, it will help to better understand and model electrocatalytic reactions.

\section{ASSOCIATED CONTENT}

\section{(S) Supporting Information}

The Supporting Information is available free of charge at https://pubs.acs.org/doi/10.1021/acs.analchem.9b04952.

Details on the SECM setup, blank voltammetry of the gold ultramicroelectrode, tip calibration voltammetry, data analysis, and sample chronoamperometry (PDF)

\section{AUTHOR INFORMATION}

\section{Corresponding Author}

*E-mail: m.koper@lic.leidenuniv.nl.

\section{ORCID $\odot$}

Leon Jacobse: 0000-0002-2825-0963

Marc T. M. Koper: 0000-0001-6777-4594

\section{Author Contributions}

${ }^{\ddagger}$ These authors contributed equally. The manuscript was written through contributions of all authors. All authors have given approval to the final version of the manuscript.

\section{Notes}

The authors declare no competing financial interest.

\section{ACKNOWLEDGMENTS}

This work was supported by the European Commission under Contract 722614 (Innovative training network Elcorel).

\section{REFERENCES}

(1) Munteanu, R.-E.; Stănică, L.; Gheorghiu, M.; Gáspár, S. Anal. Chem. 2018, 90 (11), 6899-6905.

(2) Joshi, V. S.; Sheet, P. S.; Cullin, N.; Kreth, J.; Koley, D. Anal. Chem. 2017, 89 (20), 11044-11052.

(3) Choi, J.; Groisman, E. A. Mol. Microbiol. 2016, 101 (6), 10241038.

(4) Chen, Q.; Liu, X.; Chen, J.; Zeng, J.; Cheng, Z.; Liu, Z. Adv. Mater. 2015, 27 (43), 6820-6827.

(5) Filotás, D.; Fernández-Pérez, B. M.; Izquierdo, J.; Kiss, A.; Nagy, L.; Nagy, G.; Souto, R. M. Corros. Sci. 2017, 129, 136-145.

(6) Liu, R.; Zhang, M.; Meng, Q.; Yuan, B.; Zhu, Y.; Li, L.; Wang, C. Electrochem. Commun. 2017, 82, 103-106.

(7) Koper, M. T. M. Chem. Sci. 2013, 4 (7), 2710-2723.

(8) Zheng, J.; Sheng, W.; Zhuang, Z.; Xu, B.; Yan, Y. Sci. Adv. 2016, 2 (3), No. e1501602.

(9) Ooka, H.; Figueiredo, M. C.; Koper, M. T. M. Langmuir 2017, 33, 9307.

(10) Kas, R.; Kortlever, R.; Yılmaz, H.; Koper, M. T. M.; Mul, G. ChemElectroChem 2015, 2 (3), 354-358.

(11) Pérez-Gallent, E.; Figueiredo, M. C.; Katsounaros, I.; Koper, M. T. M. Electrochim. Acta 2017, 227, 77-84.

(12) Diaz-Morales, O.; Ferrus-Suspedra, D.; Koper, M. T. M. Chem. Sci. 2016, 7 (4), 2639-2645.

(13) Wencel, D.; Abel, T.; McDonagh, C. Anal. Chem. 2014, 86 (1), $15-29$.

(14) Wang, L.; Li, M.; Li, W.; Han, Y.; Liu, Y.; Li, Z.; Zhang, B.; Pan, D. ACS Sustainable Chem. Eng. 2018, 6 (10), 12668-12674.

(15) Mirkin, M. V.; Horrocks, B. R. Anal. Chim. Acta 2000, 406 (2), 119-146.

(16) Ayemoba, O.; Cuesta, A. ACS Appl. Mater. Interfaces 2017, 9 (33), 27377-27382.

(17) Zhou, J.; Ma, H. Chem. Sci. 2016, 7 (10), 6309-6315.

(18) Yang, K.; Kas, R.; Smith, W. A. J. Am. Chem. Soc. 2019, 141 (40), 15891-15900.

(19) Rudd, N. C.; Cannan, S.; Bitziou, E.; Ciani, I.; Whitworth, A. L.; Unwin, P. R. Anal. Chem. 2005, 77 (19), 6205-6217.

(20) Fuladpanjeh-Hojaghan, B.; Elsutohy, M. M.; Kabanov, V.; Heyne, B.; Trifkovic, M.; Roberts, E. P. L. Angew. Chem., Int. Ed. 2019, 58 (47), 16815-16819.

(21) Bowyer, W. J.; Xie, J.; Engstrom, R. C. Anal. Chem. 1996, 68 (13), 2005-2009.

(22) Kakooei, S.; Ismail, C.; Ari-Wahjoedi, B. Int. J. Mater. Sci. Innov. 2013, 1 (1), 62-72.

(23) Nadappuram, B. P.; McKelvey, K.; Al Botros, R.; Colburn, A. W.; Unwin, P. R. Anal. Chem. 2013, 85 (17), 8070-8074.

(24) Ouattara, L.; Fierro, S.; Frey, O.; Koudelka, M.; Comninellis, C. J. Appl. Electrochem. 2009, 39 (8), 1361-1367.

(25) Huang, W. D.; Cao, H.; Deb, S.; Chiao, M.; Chiao, J. C. Sens. Actuators, A 2011, 169 (1), 1-11.

(26) Jović, M.; Hidalgo-Acosta, J. C.; Lesch, A.; Costa Bassetto, V.; Smirnov, E.; Cortés-Salazar, F.; Girault, H. H. J. Electroanal. Chem. 2018, 819, 384-390.

(27) Kiss, A.; Nagy, G. Electroanalysis 2015, 27 (3), 587-590.

(28) Jovanovič, P.; Hodnik, N.; Ruiz-Zepeda, F.; Arčon, I.; Jozinović, B.; Zorko, M.; Bele, M.; Šala, M.; Šelih, V. S.; Hočevar, S.; et al. J. Am. Chem. Soc. 2017, 139 (36), 12837-12846.

(29) Alam, A. U.; Qin, Y.; Nambiar, S.; Yeow, J. T. W.; Howlader, M. M. R.; Hu, N. X.; Deen, M. J. Prog. Mater. Sci. 2018, 96, 174-216.

(30) Morris, C. A.; Chen, C. C.; Ito, T.; Baker, L. A. J. Electrochem. Soc. 2013, 160 (8), H430-H435.

(31) Vishnu, N.; Kumar, A. S.; Pan, G. T.; Yang, T. C. K. Sens. Actuators, B 2018, 275, 31-42.

(32) Zuaznabar-Gardona, J. C.; Fragoso, A. Sens. Actuators, B 2018, 273, 664-671.

(33) Lindino, C. A.; Bulhões, L. O. S. Anal. Chim. Acta 1996, 334 (3), 317-322.

(34) Ryu, J.; Wuttig, A.; Surendranath, Y. Angew. Chem., Int. Ed. 2018, 57 (30), 9300. 
(35) Yokoyama, Y.; Miyazaki, K.; Miyahara, Y.; Fukutsuka, T.; Abe, T. ChemElectroChem 2019, 6, 4750-4756.

(36) Figueiredo, M. C.; Arán-Ais, R. M.; Climent, V.; Kallio, T.; Feliu, J. M. ChemElectroChem 2015, 2 (9), 1254-1258.

(37) Lu, M.; Compton, R. G. Analyst 2014, 139 (10), 2397-2403.

(38) Lu, M.; Compton, R. G. Analyst 2014, 139 (18), 4599-4605.

(39) Wildgoose, G. Talanta 2003, 60 (5), 887-893.

(40) Pöller, S.; Schuhmann, W. Electrochim. Acta 2014, 140, 101107.

(41) Botz, A.; Clausmeyer, J.; Öhl, D.; Tarnev, T.; Franzen, D.; Turek, T.; Schuhmann, W. Angew. Chem., Int. Ed. 2018, 57 (38), 12285-12289.

(42) Michalak, M.; Kurel, M.; Jedraszko, J.; Toczydlowska, D.; Wittstock, G.; Opallo, M.; Nogala, W. Anal. Chem. 2015, 87, 1164111645 .

(43) De Voogd, J. M.; Van Spronsen, M. A.; Kalff, F. E.; Bryant, B.; Ostojic, O.; Den Haan, A. M. J.; Groot, I. M. N.; Oosterkamp, T. H.; Otte, A. F.; Rost, M. J. Ultramicroscopy 2017, 181, 61-69.

(44) Monteiro, M. C. O.; Koper, M. T. M. Electrochim. Acta 2019, $325,134915$.

(45) Jacobse, L.; Raaijman, S. J.; Koper, M. T. M. Phys. Chem. Chem. Phys. 2016, 18 (41), 28451-28457.

(46) Tsutsumi, H.; Furumoto, S.; Morita, M.; Matsuda, Y. J. Colloid Interface Sci. 1995, 171 (2), 505-511.

(47) Touzalin, T.; Joiret, S.; Maisonhaute, E.; Lucas, I. T. Anal. Chem. 2017, 89 (17), 8974-8980.

(48) Cobb, S. J.; Ayres, Z. J.; Newton, M. E.; Macpherson, J. V. J. Am. Chem. Soc. 2019, 141 (2), 1035-1044.

(49) Amphlett, J. L.; Denuault, G. J. Phys. Chem. B 1998, 102 (49), 9946-9951.

(50) Izquierdo, J.; Knittel, P.; Kranz, C. Anal. Bioanal. Chem. 2018, 410 (2), 307-324.

(51) Ballesteros Katemann, B.; Schulte, A.; Calvo, E. J.; KoudelkaHep, M.; Schuhmann, W. Electrochem. Commun. 2002, 4 (2), 134138.

(52) Eckhard, K.; Schuhmann, W. Analyst 2008, 133 (11), 14861497.

(53) Maljusch, A.; Senöz, C.; Rohwerder, M.; Schuhmann, W. Electrochim. Acta 2012, 82, 339-348.

(54) Critelli, R. A. J.; Bertotti, M.; Torresi, R. M. Electrochim. Acta 2018, 292, 511-521. 